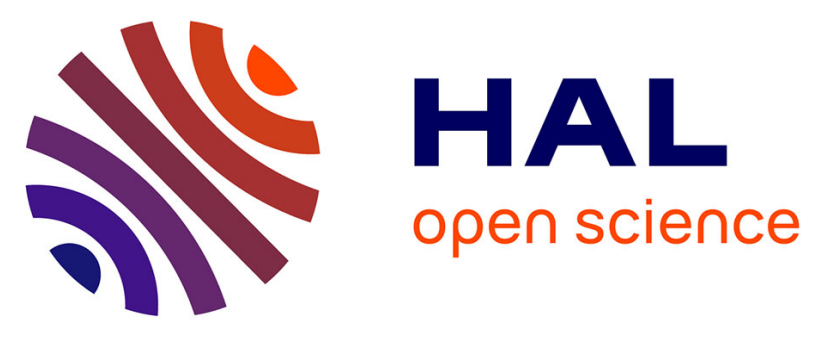

\title{
Geometry vs Semantics: Open Issues on 3D Reconstruction of Architectural Elements
}

\author{
Livio de Luca, David Lo Buglio
}

\section{To cite this version:}

Livio de Luca, David Lo Buglio. Geometry vs Semantics: Open Issues on 3D Reconstruction of Architectural Elements. Marinos Ioannides; Ewald Quak. 3D Research Challenges in Cultural Heritage, 8355, Springer Berlin Heidelberg, 2014, Lecture Notes in Computer Science, 978-3-662-44629-4 978-3-662-44630-0. 10.1007/978-3-662-44630-0_3 . hal-02891732

\section{HAL Id: hal-02891732 \\ https://hal.science/hal-02891732}

Submitted on 7 Jul 2020

HAL is a multi-disciplinary open access archive for the deposit and dissemination of scientific research documents, whether they are published or not. The documents may come from teaching and research institutions in France or abroad, or from public or private research centers.
L'archive ouverte pluridisciplinaire HAL, est destinée au dépôt et à la diffusion de documents scientifiques de niveau recherche, publiés ou non, émanant des établissements d'enseignement et de recherche français ou étrangers, des laboratoires publics ou privés. 
See discussions, stats, and author profiles for this publication at: https://www.researchgate.net/publication/312722549

\section{Geometry vs Semantics: Open Issues on 3D Reconstruction of Architectural} Elements

Chapter · January 2014

DOI: 10.1007/978-3-662-44630-0_3

\section{CITATIONS}

6

2 authors:

0

Livio De Luca

French National Centre for Scientific Research

120 PUBLICATIONS 1,258 CITATIONS

SEE PROFILE
READS

49

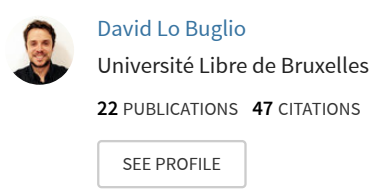

Some of the authors of this publication are also working on these related projects:

Project Morphological characterization of architectural elements View project

Project Genius Loci View project 


\title{
Geometry vs Semantics : Open Issues on 3D Reconstruction of Architectural Elements
}

\author{
Livio De Luca ${ }^{1}$, David Lo Buglio ${ }^{1,2}$ \\ UMR 3495 CNRS / MCC MAP Gamsau - Marseille, France. \\ \{livio.deluca, david.lobuglio\}@map.archi.fr \\ Laboratoire AlICe - Faculté d'Architecture La Cambre Horta, \\ Université Libre de Bruxelles (ULB) - Brussel, Belgium. \\ david.lo.buglio@ulb.ac.be
}

\begin{abstract}
Three-dimensional representation is becoming an effective support for the documentation of the state of conservation of heritage artefacts, for the study of its transformations and for cultural diffusion. 3D digitization technologies now offer effective means to observe and analyze historic buildings with more accuracy, completeness and timeliness. Nevertheless, this produces a real problem of information overload. The growing mass of uninterpreted data make emerge a need for innovative methodologies assisting data processing, sorting and analysis by researchers who want to use it for advancing the knowledge of cultural heritage. Exploring the informational value of these new representation systems allows introducing new approaches to the analysis of artefacts so distant in space but so close in features (typologies, styles, compositional rules, etc.). This chapter presents some research avenues for defining a geometric/semantic description model of architectural elements in order to integrate the informative value of $3 \mathrm{D}$ digitization in intelligible representations.
\end{abstract}

Keywords: Architecture, heritage, representation, 3D digitization, epistemology, knowledge, geometry, semantics.

\section{Introduction}

During the past three decades, the fields concerning heritage documentation took advantage of digital and survey techniques development. One can consider that this development has been done in favour of acquisition and processing work (in order to reconstruct and document complex architectural objects). The realization of 3D models of heritage buildings in their current state, as the hypothetical reconstruction of past states, requires a powerful methodology able to not only capture and digitally reconstruct fine geometric details and appearances of such objects, but also to interpret their morphology in order to compose intelligible representations. Nowadays, 
$3 \mathrm{D}$ data is a critical component to permanently record the shape of impor- tant objects and sites so that, at least in digital form, they might be handed down to future generations. Reality-based 3D modeling today has become an effective solution for providing dense and accurate $3 \mathrm{D}$ representations which are the basis for further uses such as documentation material production, restoration and conservation policies, physical replicas, digital inventories, etc. Various tools and emerging technologies [1], [2] have been integrated into approaches for the 3D reconstruction of buildings in order to reproduce the morphological complexity of heritage buildings and to support different analysis requirements [3].

If the (constantly growing) mass of data has effectively enabled to approach the reconstruction of complex geometries, this overgrowth (of data) does not seem to increase the level of intelligibility of the representations produced.

The scientific analysis of documentary resources has benefited from informatics solutions regarding the organization and management of data. Many solutions have been developed in order to improve the management of digital contents using a formal structure for describing implicit and explicit concepts and relations used in cultural heritage documentation [4].

If much of the work has focused on the semantic characterization of generic 3D shapes [5], very little seems to deal with integrating heterogeneous data in a display device referring to the building morphology [6]. Solutions that could be applied to this problem are certainly GIS (geographical information system) and BIM (building information modeling) systems. However, in order to conceive an information system for the study of heritage buildings that is able to really exploit the potential of realitybased $3 \mathrm{D}$ representations, a more profound analysis of data structuring problems must be done.

In order to anticipate a foreseen methodological deficit, it is necessary to provide some reflections for the creation of representation systems that are able to enrich the informational value of the documents produced.

Behind the technical advances of 3D representation, many difficulties are arising with the creation, the sharing and the dissemination of digital models (models whose data continues to grow). This leaves open a field of epistemological questions on the practices of the architectural representation.

But more specifically, these questions must help to position the research beyond the simple purpose of development of tools and techniques, so it provides to the field of heritage documentation methodological reflections on the scientific issues surrounding the representation of artefacts.

The study of means must also pay attention to the specific cognitive issues belonging to the architectural representation in order to take into account the link between perception and the semiotic foundations of communication. This concern assumes that the representation of an architectural object cannot escape from our vision and for the knowledge we mobilize for its understanding.

We attempt here to provide reflection avenues for innovative development of representation systems (and information technologies) that can constitute new tools for investigation and scientific visualization, assuming the dimensions of "complexity" and "intelligibility" within the same graphical space.

Three-dimensional representation of the built environment is becoming an effective support for documenting architectural artefacts, study of built deteriorations, 
cultural diffusion and promotion of heritage. In this context, new technologies involved in 3D digitization give new means for observing built environment with more accuracy, more completeness and less time. However, the application of these new technologies produces a problem of "data" overload. The growing mass of points clouds, 3D models and un-interpreted data require innovative methodologies for knowledge processing, sorting and finally analysis.

After a brief assessment of the results obtained within the context of a critical study of the relationship between the 3D digitization of the built heritage and the informational contribution of digital models, we presented in a paper, some avenues of research in the fields of heritage representation [7]. More generally these tracks questioned the ability of representations to be transformed into tools of analysis, scientific evaluation and transmission of knowledge [8]. This transmission through the figure must be able to associate the specific knowledge available on the artefact with generic knowledge drawn from the theory of architecture [9].

\section{Analysis of the informational value of architectural digital representations}

In order to meet the supposed "lack of" intelligibility deficit, we suggested a first approach to objectify the informational content of 3D digitization of architectural artefacts [7]. The first results of this critical analysis have enabled a better understanding of how certain modeling methods or digitization techniques contribute to improve the level of architectural knowledge transmitted by the representations produced. As it is difficult to imagine that the single use of technology can replace the cognitive contribution of a human operator, the study also suggested to evaluate the contribution of the operator in the semantic enrichment of the digital model.

The lasergrammetry and photogrammetry, as techniques for recording dimensional and colorimetric aspects of a building, are now used to reconstruct the visual appearance of complex architectural morphologies. With these advances, we might think that the representation of territory at a 1:1 scale suggested by Borges is not so far [10] and the technologies used in the survey campaigns seems to be the primary source of the enrichment of the architectural representation. However, these tools respond first to the requirements of accuracy and completeness and are far from the cognitive issues of the architectural representation [11]. These issues (surrounding the architectural representation) are based on a paradigm that exists since the Italian Renaissance and that considers the representation (in a survey process) as a space which overlays, via the figure, the specific and generic knowledge about the artefact.

To conduct this review on methodological aspects, the observations focused on a series of digitization works. The objective was to evaluate the set of information that describes the architectural object in order to measure the information gain provided by the document, regarding the employed requirements and means. The observation was conducted from automated reconstruction processes up to manual restitution works.

The mobilized criteria for the analysis were defined on the basis of an empirical observation of digitization works as well as on the concept of "informational 
modeling" developed by Blaise and Dudek [12]. Starting from this concept, they set forth certain methodological approaches to increase the intelligibility of the informational content of the 3D model. Beyond the facilities offered by this guide of "good practices" and by the logic of symmetry, these rules offer a legitimate theoretical basis to locate some informational properties of a representation.

Without going into detail, these observations have demonstrated a wider cognitive commitment of the operator as he approaches a manual restitution process. This relatively clear causality effect also indicates the existence of a double epistemological problem.

- The distancing of the operator in an automated reconstruction process (photogrammetric or lasergrammetric reconstruction by polygonal meshing) leads to a gain of objectivity of the representation produced. In contrast, the use of technologies enabling high levels of precision does not seem to be a pledge of a substantial cognitive contribution.

- In parallel, the analytical mechanisms of reading and interpreting present in a "manual" restitution process induce a form of subjectivity. It presents also a great interest to the cognitive enrichment of the model. However, the digitization observed showed us that a representation that does not express the relative level of knowledge may hardly be used as a tool for scientific evaluation [7].

\section{Five restitution processes}

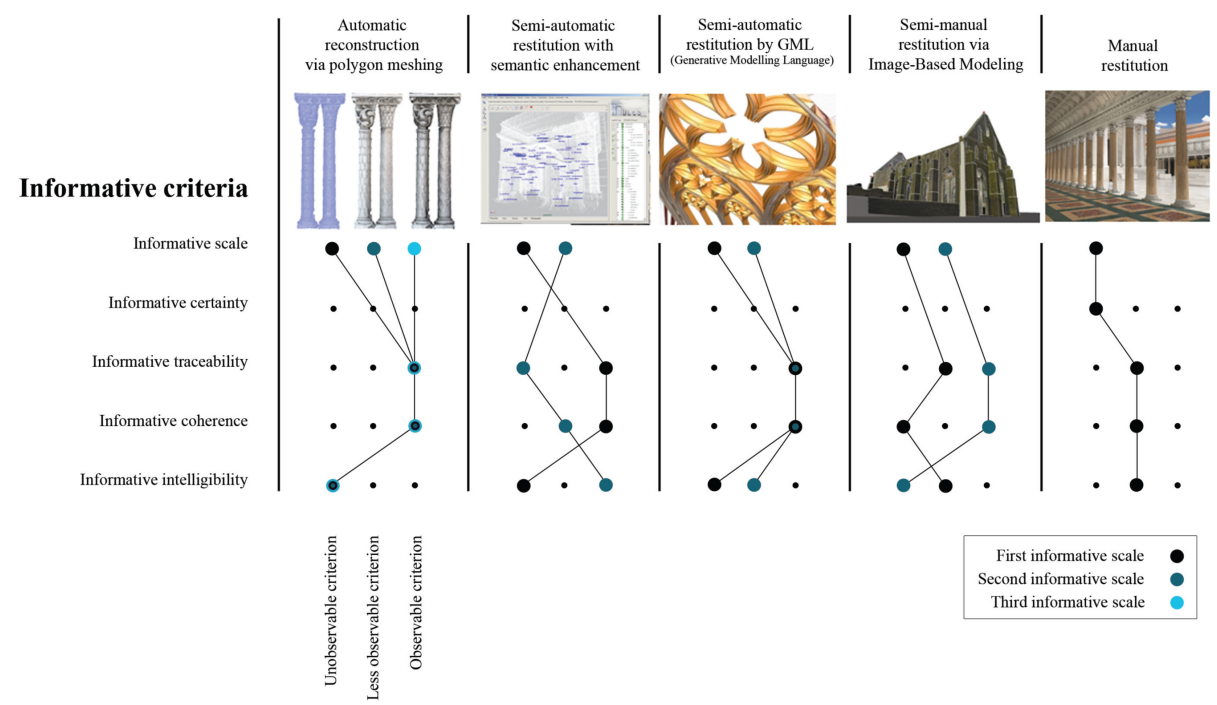

Fig. 1. Analysis of the information content of five restitution processes: 
1. Automatics reconstruction via polygon meshing [13]. Column of the Abbey of SaintGuilhem-le-désert. Visual levels (geometry, textures, occlusion + textures).

2. Semi-automatic restitution with semantic enhancement [14]. Architectural semantisation of the point cloud of the Arc de Triomphe. See also Nubes project.

3. Semi-automatic restitution by GML [15]. Shape variation of a Gothic Window Tracery created in GML.

4. Semi-manual restitution via Image-Based Modeling. Image-based modeling of the current state of the refectory of Villers-la-Ville Abbey (Belgium). Digitization done by Laboratoire AlICe, Faculté d'Architecture La Cambre Horta, Université Libre de Bruxelles (ULB).

5. Manual restitution of the temple of Mars Ultor [16].

\section{Between complexity and intelligibility}

\subsection{Modeling semantically-enriched 3D architectural shapes}

The analysis of architectural shapes may be led by the identification of the process allowing its geometrical construction. However, the codes of architectural representation can always help in this stage, which remains the most difficult phase of building reconstruction. To give an example, one can take the geometrical representation of a simple column: this element, far from being a simple cylinder, is characterized by a pace (truncated, bent bottom, bent third, or reinflated) and transitions as the cimbia (moulding softening the meeting of the shaft with the base) or the astragale (body of mouldings separating the capital from the shaft [17] ). Moreover, certain proportions regulate its dimensions [18]. This type of observation can be made for almost every part of a building. The study of shape has a double finality: the first one is that of representation, the second one is the surveying of the object. If one analyzes these two moments of the study, one easily realizes that they are in a strictly interdependent relation, which is neither hierarchical, nor sequential. To draw an element, its shape should be known, to know its shape, it should be measured, but to measure it, it is necessary to decipher its geometrical nature. In this sense, one of the most effective ways to define the architectural survey is to consider it as the rebuilding of the project. The surveying is indeed a reverse process in which, starting from an existing object, one rebuilds the process of its realization, and one interprets the idea of design which comes before its realization [19].

Within the logical continuity with the history of the architectural representation, our general purpose consists of considering the digital surveying of an historic building as a cognitive act: the moment in which one can analyse relevant relations between shape, geometry and architectural sense. Our works start from the idea that even if today one can use new (and sophisticated) tools, specific requirements coming from the architectural documentation and conservation fields remain and need the 
development of "intelligible" representations. In this sense, the alignment of emerging techniques to conventional codes of architectural representation is a main issue.

The application of geometry to the description and analysis of the architectural shape necessitates the reduction of multiplicity into intelligibility. Examples of this approach may be found in various fields and applied to the geometrical understanding of shapes or varied phenomena [20]. In the same way, starting from a geometrical analysis of the various parts of a building, and by having as an objective its geometrical and semantic description, we proposed a method for the geometrical reconstruction starting from profiles [21]. This method is founded on the analysis of invariant and morphological specificities one can extract from a semantic segmentation of the building morphology. Throughout the history of architecture, the morphological complexity of shapes was always influenced by the methods of geometrical control that made their conception possible; examples of these methods are the descriptive geometry [22] or stereotomy [23], [24]. Based on a study of the principles subjacent to these control methods of architectural shape, one can then identify, on one side, relevant information to be extracted from survey (profiles in a point cloud for example) and, on the other side, the process of construction better adapted to ensure the geometrical restitution of elements.

Starting from this first issue, we worked on the definition of a generic formalism for the semantic representation of classical elements [25]. The approach we defined in order to describe architectural elements takes into account three distinct dimensions:

- The interpretation of knowledge relating to shapes

- The definition of methods allowing their geometrical modeling

- The identification of the relations between the sub-parts of shapes

We organize the formalization of the element according to relations between two parallel levels of description: geometrical and semantic. The first makes it possible to rebuild shapes in three dimensions; the second makes it possible to organize parts according to the vocabulary of the architect. Geometrical description is based on the relations among three types of generic nodes (conceptual elements of the formalism) describing the construction of the element from the definition of its geometrical atoms (lowest-level geometrical entities) to the complete generation of its surfaces.

- Atoms: a node characterized by a structure of information concerning the geometrical construction, the spatial transformation and the constraints of an atomic entity.

- Profiles: a level, which allows the grouping of the mouldings according to the construction plans.

- Surfaces: a level which uses specific nodes for the generation of surfaces starting from profiles 

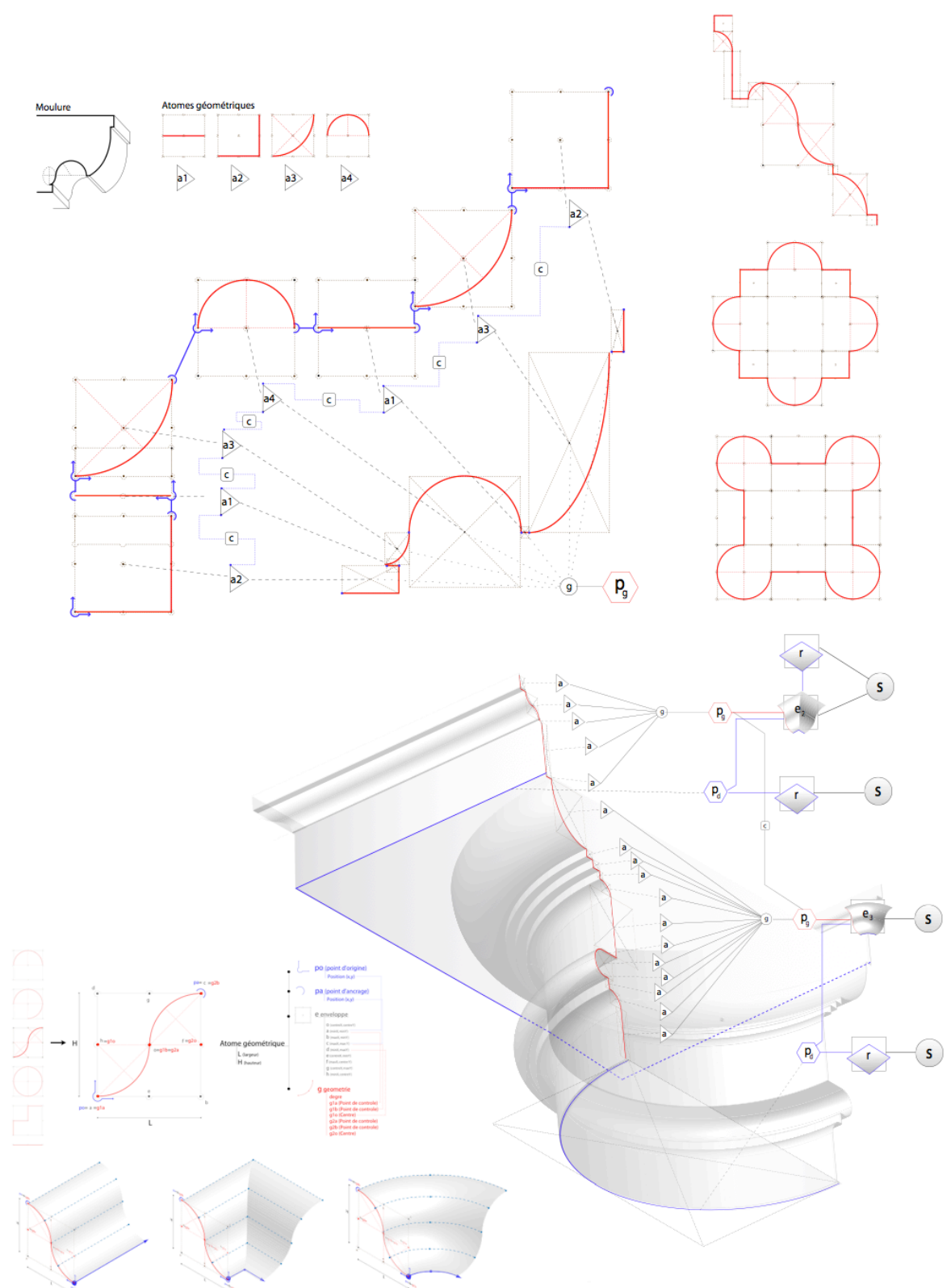

Fig. 2. Atoms, profiles and surfaces of the generic formalism for the geometric description of classical elements

These atoms are the only entities of the formalization for which we provide geometrical information (control points of a line or of a curve): indeed, the generation of the whole element surface is based exclusively on constraint relations, grouping 
operations and modeling functions. Figure 2 shows the geometrical construction of a doric capital described in Palladio's treaty [8] and obtained by a simple combination of geometrical atoms gathered in two generating profiles and extruded along two directing paths. For the formalization of the element we connect atoms according to the sequence of mouldings. Once mouldings are suitably proportioned (introducing dimensional values), we gather them in two generating profile nodes according to the respective modeling procedures. The semantic description level is defined by a structure of concepts organized around the geometrical description. Nodes of the semantic description, on one side, are connected to architectural terms, and on the other, gather the geometrical description elements in a hierarchical structure: atoms/mouldings/parts of the profile. We use formalized primitives in order to constitute a library of architectural elements by the simple declaration of a sequence of mouldings (see Fig. 3)

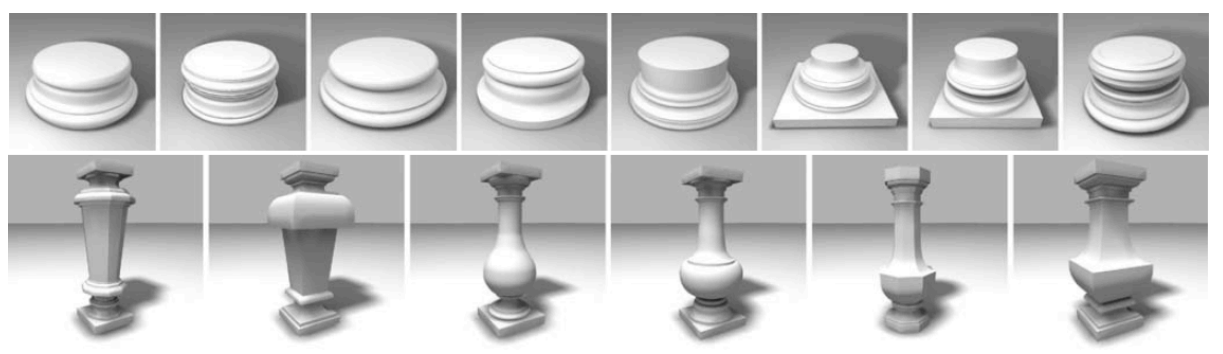

Fig.3 . Bases and balusters modelled by declaration of a sequence of geometrical atoms

\subsection{Reasoning from semantics to geometry and vice-versa}

The potential of the image-based 3D reconstruction approaches with respect to rangebased / LiDAR methods is getting more and more evident, thanks to the latest developments in dense image matching [26], [27], [28], [29], [30] and the availability of web-based and open-source processing tools (e.g. Photosynth, 123DCatch, Apero, MicMac, etc.). These developments based on photogrammetry and computer vision methods have shown very promising results and renewed attention for image-based 3D modeling as an inexpensive, robust and practical alternative to 3D scanning.

The introduction of new protocols for acquisition and processing of spatial data [31] has given rise to new research perspectives. The opportunity to combine records, geometric analysis and characterisations about several artefacts could also be used for developing new approaches for shape classification and interpretation. The availability of flexible solutions for collecting morphological data on masses of artefacts allow considering the shape analysis as a fundamental moment for reasoning about the relationships between geometry and semantics and in a bidirectional analysis approach. 

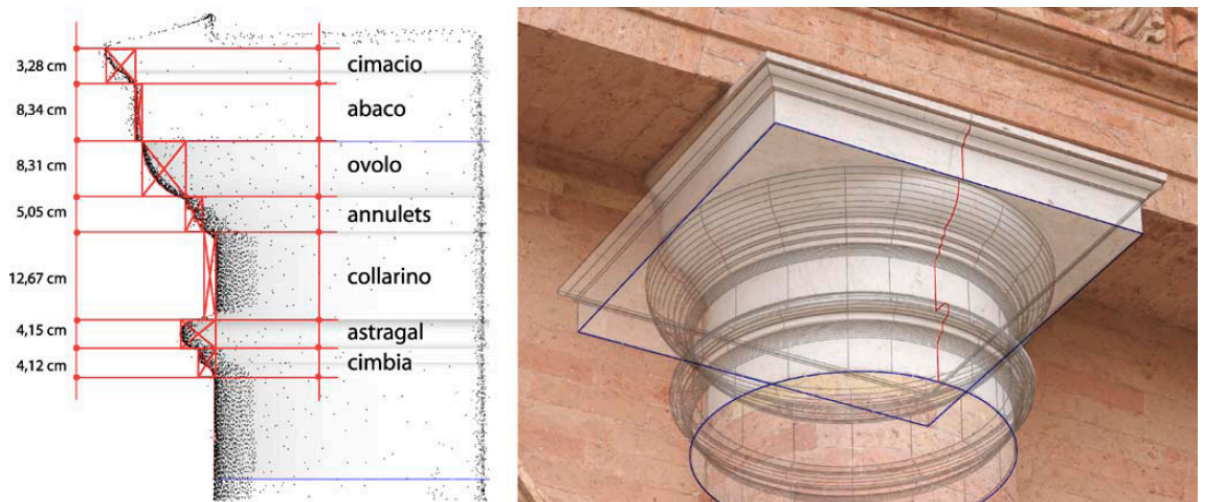

Fig.4 . Primitive adjusted on the point cloud. On the left, vertical profile with dimensional information; on the right, primitive projected on a photography oriented on the point cloud

In the first case (from semantics to geometry), the idea is to explore ways to insert architectural semantics within the surveying procedures (by associating them with dimensional information). This would allow an immediate reading of dimensional parameters corresponding to architectural concepts that characterize the artefact (see fig. 4).

This kind of approach can provide great advantages in the 3D reconstruction process. A correct (and knowledge-based) interpretation of data prevents the production of unrealistic architectural shapes and would provide models linked to specific vocabularies and grammars. Indeed, we believe that the modeling of architectural elements must refer to the formal description of characters defined by the codes of architectural representation (in relation to historical periods and stylistic trends). In this context, significant efforts on formalizing typical architectural elements can be conducted, including the study and re-interpretation (in the context of the digital modelling domain) of architectural treatises (description of typical shapes, compositional rules, constraints of positioning and orientation, principles of scaling, etc..).

In the second case (from geometry to semantics) it's necessary to investigate solutions for the shape segmentation but also the issues related to semantic annotation. Indeed, for some years now the communities involved in the heritage documentation seem gradually take over the problems related to intelligibility deficit. There are now numerous studies concerned with the exploitation of non-interpreted data. Indeed, the geometric description and the analysis of architectural shapes require a reduction of multiplicity to intelligibility.

We recently started working on a shape analysis method combining a bottom-up approach, in which the meaning of the elements comes from the combination of a low-level, and a top-down morphological analysis, which takes advantage of prestructured knowledge (see Fig. 5).

This kind of approach is therefore based on the identification of generic models that can integrate multiple instances (e.g. objects belonging to the same stylistic trend) by bringing out common morphological features by means of the identification of semantic/geometric classes. 

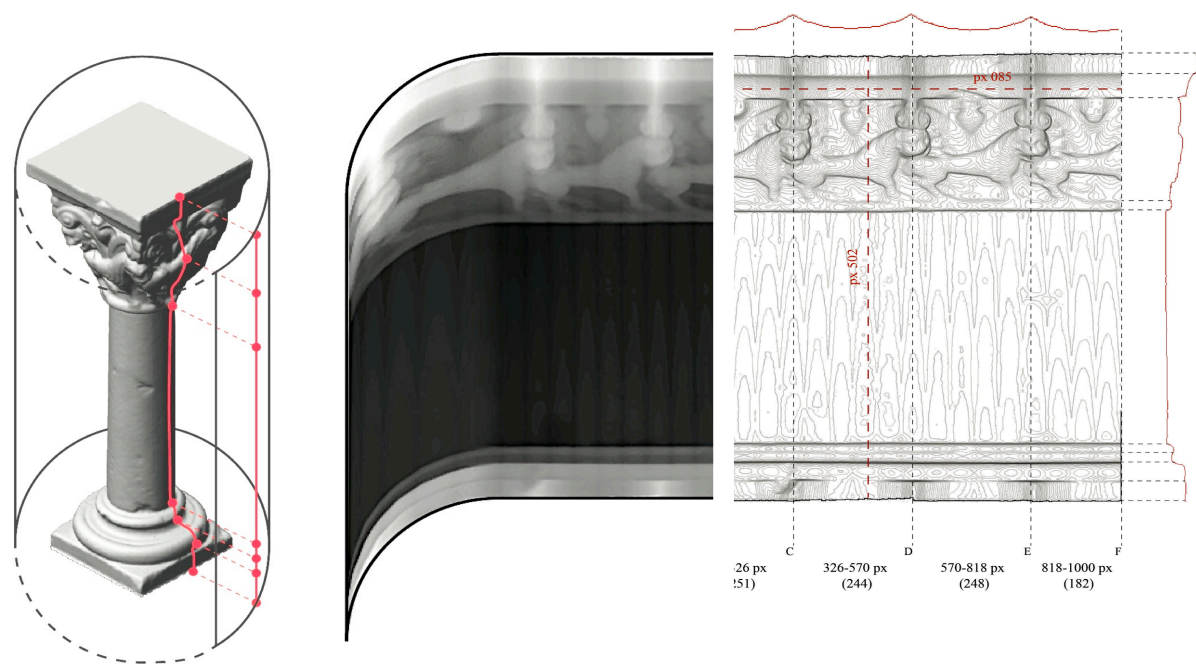

Fig. 5. Generation of a depth map from the polygonal mesh and analysis of geometric discontinuities and profiles directly on the map.

The digital segmentation of architectural digitization could follow a top-down approach, which takes advantage of pre-structured knowledge of the domain or bottom-up approach, in which the meaning of the elements comes from a "free" morphological analysis. Concerning the top-down approach, it is necessary to study the techniques of semi-automatic segmentation in order to identify meaningful parts (a base, a shaft and a capital of a column) corresponding to well-defined concepts (in terms of architectural vocabulary). The transfer of segmentation and semantic annotation to unique items, even to the entire model, is studied a second time. The study on segmentation and semantic annotation should complement an analysis of the geometric similarity used to compare elements or architectural objects between them. This would create a library of architectural forms and morphological criteria organized around pre-structured knowledge.

As it is explained above, it seems also necessary to complete this first step with a bottom-up approach that would take advantage of the multiplicity of acquired data. In this case, the meaning of the elements would come from a "free" morphological estimation and not from a shape thesaurus. The "free" estimation corresponds to the opportunity to study without bias on the results, the point aggregate, the curvatures of surfaces and volumes of the architectural elements.

The use of statistical analysis would permit to find correspondences between different geometric entities. Morphological comparisons that can be done on a set of shapes offer opportunities to study similarities in a collection of architectural elements (Fig. 6). Indeed, by establishing common geometric observation criteria and multiplying comparisons between elements, it is possible to identify morphological signatures that can contribute, in a second step, at the semantic characterization of a 
collection. This approach is therefore based on the self-expansion of a large amount of data. The medium-term challenges of this approach are:

- to establish new shape classification criteria. The comparison of architectural objects on the basis of geometric similarities aims to create libraries of architectural shapes organized around pre-structured knowledge.

- to question architectural treaties with the classification work (through the geometrical analysis of the typical shapes, the composition rules, the principles of scale, the positioning constraints, the orientation, etc...).

- to study the variability of architectural elements. In the field of built heritage, the morphological signature (or theoretical model) of a collection of elements can serve as the basis for the study of their variability in space and time. In addition, it can also have an impact on the understanding of the evolution of a style. In the continuation, the use of self-extension mechanisms can provide useful answers to observe unclassified and uninterpreted shapes.

The study is therefore based on a dual approach.

On the one hand, the study of the typical characteristics extracted from the formalization of architectural knowledge associated with an existing semantic characterization conduct "by intention" (integration of pre-defined knowledge);

On the other hand, the definition of an analysis strategy "by extension" (identification of a model that can integrate multiple instances) able of bringing out the common morphological characters of elements collections analyzed mainly through geometric criteria. Studies on both aspects should succeed in the identification of semantic/geometric classes.
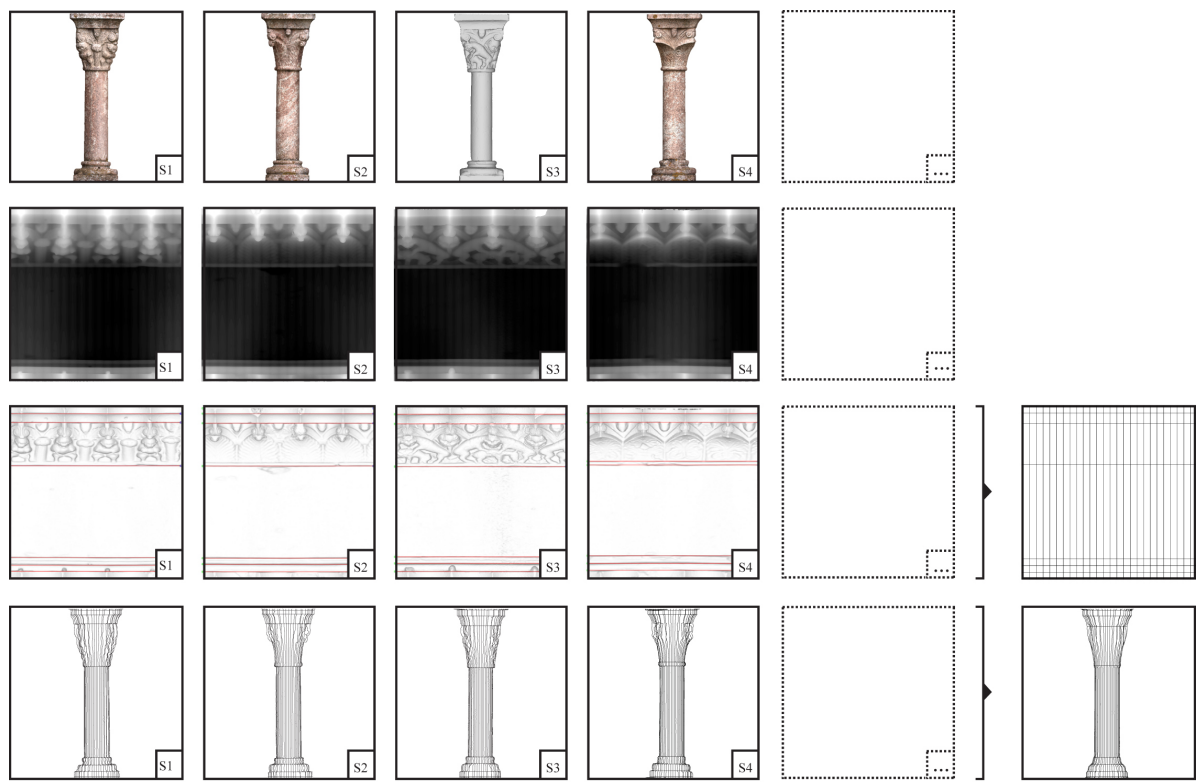

Fig. 6. A comparative analysis of four columns : from left to right, the polygonal mesh, the produced depth map, the extracted discontinuities, the created simplified geometric reconstruction and the average values. 


\subsection{Hybridization of the digital instance with the geometrical/ semantic model in a $3 D$ representation}

As it is written in the introduction, digitization generally responds to one of these two concepts: multiplicity or intelligibility. If the multiplicity refers to un-interpreted and visible digital instance of the architectural object, the notion of intelligibility crossreference to the theoretical model of the same object. In other words, it expresses its ability to evoke a universe of knowledge that can inform us about the semantic construction of an architectural element. The shift from multiplicity to intelligibility presupposes the presence of a human operator whose aim is to filter, reduce and interpret all data collected in order to retain only those which will replenish the theoretical model. This is essential to produce a set of relevant information in relation to the analytical objectives pursued.

But beyond the analytical issues, it is necessary to think about the distance between the instance and its theoretical model, and how these two concepts can be articulated in a unique representation system.

It would be interesting to define a geometric/semantic model allowing a hybridization of the complexity (representing instances without interpretation) with semantic concepts (linked to the notion of intelligibility). The suggested procedure (see Fig. 7) thus follows these steps [32]:

- Interactive and semi-automatic 3D reconstruction based on several methods that depend directly on the morphological complexity:

- Basic adaptation of geometric primitives on an extension from the geometry (bottom) to architecture (up).

- Computing a disparity map between the original item (dense points cloud or polygons) and the simplified elements (primitive, lightweight mesh, etc.).

- Mapping of visual and geometric information (from the original elements) on the simplified elements by creating "enriched textures" (depending on the UV setting).
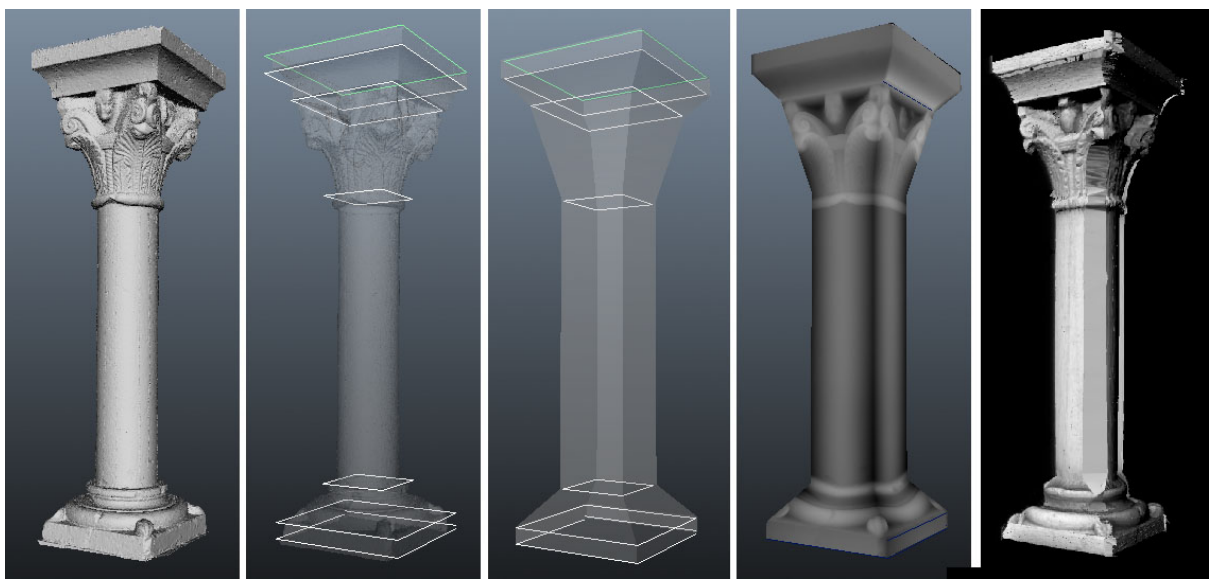

Fig. 7. Process of mapping visual information and geometry on geometric primitives through the creation of "enriched textures". 


\section{Conclusions}

Based on a partial assessment of methodological deficiencies surrounding the techniques and methods of architectural heritage digitization, this chapter highlights various indicators to better assess the informational value of an architectural representation. But beyond this first aspect, this study has two objectives. First, it brings out the cognitive dimension present in the digitization work and second, it attempts to establish the relationship between the concepts of multiplicity of data and the intelligibility of the theoretical model.

The studies about the instance similarities or detailed digitization from simplified geometrical/semantic models constitute a relevant research avenue allowing to visualize the gap between a theoretical model and a digital instance. On the other hand, this approach opens up interesting prospects for a closer connection between the detailed documentation of an architectural object and its description in an analytic language (parametric). In other words, it helps to consider the description of an object in a language that separates the formal analysis from the visible form.

\section{References}

1. Boehler, W., Marbs, A.: 3D scanning instruments. In: Proceedings of the CIPA WG 6th Int. Workshop on Scanning for Cultural Heritage, Corfu, Greece (2002)

2. Debevec, P., Taylor, C., Malik, J.: Modeling and rendering architecture from photographs: a hybrid geometry and image-based approach. In: Proceedings of SIGGRAPH, pp 11--20. New Orleans, LA (1996)

3. El Hakim, SF., Beraldin, A., Picard, M., Vettore, A.: Effective 3D modeling of heritage sites. In: Proceedings of the 4th Int. Conf. on 3D digital Imaging and Modeling, pp 302309. Canada (2003)

4. Doer, M.: The CIDOC CRM: an ontological approach to semantic interoperability of metadata. In: AI Magazine, Special Issue, vol. 24 n³, pp 75--92. (2003)

5. Attene, M., Robbiano, F., Spagnuolo, M., Falcidieno, B.: Characterization of 3D shape parts for semantic annotation. In: Computer Aided Des, vol. 41 n 10, pp 756--63. (2009)

6. Manferdini, AM., Remondino, F., Baldissini, S., Gaiani, M., Benedetti, B.: 3D modeling and semantic classification of archaeological finds for management and visualization in 3D archaeological databases. In: Proceedings of the 14th Int. Conf on Virtual Systems and MultiMedia (VSMM), pp 221-228. Cyprus (2008)

7. Lo Buglio, D., De Luca, L.: Critical review of 3D digitization methods and techniques applied to the field of architectural heritage: methodological and cognitive issues. In: Vast 2011. The 12th International Symposium on Virtual Reality, Archaeology and Cultural Heritage, pp. 5--12. Eurographics press, Prato (2011)

8. Palladio, A. (1750): The Four Books of Architecture. Dover Publications, New York (1965)

9. Blaise, J.-Y., Dudek, I.: Modélisation informationnelle: concepts fondamentaux. Visualiser pour raisonner sur des connaissances architecturales. In: MIA Journal, vol. 1, pp. 143--154 (2006)

10. Borges, J.L.: De la rigueur de la science. In: L'auteur et autres textes. pp. 221--221. Gallimard, Paris (1982)

11. Mediati, D.: L'occhio sul mondo per una semiotica del punto di vista. Rubbettino, Soveria Mannelli (2008) 
12. Blaise, J.-Y., Dudek, I.: Modélisation Informationnelle, Imprimerie du CNRS - Provence (2006)

13. De Luca, L., Driscu, T., Labrosse, D., Peyrols, E., Berthelot, M.: Digital Anastylosis of the cloister of Saint-Guilhem-le-Desert. In: Research in Interactive Design. Proceedings of IDMME-Virtual Concept 2008. vol. 3. Beijing (2008)

14. UMR 3495 CNRS/MCC MAP Gamsau: Nubes project. Find June 26, 2011, from http://www.map.archi.fr/nubes/introduction/projet.htm

15. Havemann, S., Fellner, D.: Generative parametric design of Gothic window tracery. In: Shape Modeling International, pp. 350--353 (2004)

16. Université de Caen De Caen Basse-Normandie: Projet de restitution. Le Plan de Rome. Restituer la Rome Antique. Find June 3, 2011, from http://www.unicaen.fr/cireve/rome/pdr_restitution.php?fichier=objectifs

17. Perouse de Montclos, JM.: Architecture vocabulaire: principes d'analyse scientifique. Imprimerie Nationale, Paris (1972)

18. Forssman, E.: Palladio e le colonne. Bollettino del Centro Internazionale di Studi di Architettura Andrea Palladio. Vicenza, Italy (1978)

19. Migliari, R., Docci, L.: Geometria e architettura. Gangemi, Rome (2000)

20. Thompson, DW., On Growth and Form. Cambridge University Press, Cambridge (1942)

21. De Luca, L.: Relevé et multi-représentations du patrimoine architectural. Définition d'une approche hybride de reconstruction 3D d'édifices. PhD Thesis, Arts et Métiers Paris Tech (CER d'Aix-en- Provence), Paris (2006)

22. Monge, G.: Géométrie descriptive. Bibliothèque Nationale de France (BNF), Paris (1799)

23. Desargues, G.: Bruillon projet d'exemple d'une manière universelle du S.G.D. Touchant la pratique du trait à preuves pour la coupe des pierres en architecture. Bibliothèque Nationale de France (BNF), Paris (1640)

24. Vallée, L.: Spécimen de coupe de pierres, contenant les principes généraux du trait et leur application aux murs, aux plate-bande, aux berceaux, aux voûtes sphériques, aux voûtes de révolution, aux voûtes à base polygonale. Bibliothèque Nationale de France (BNF), Paris (1853)

25. De Luca, L., Veron, P., Florenzano, M. : A generic formalism for the semantic modeling and representation of architectural elements. In: The Visual Computer, vol. $23 \mathrm{n}^{\circ} 3$, pp. 181-205. Springer, Heidelberg (2007)

26. Hirschmueller, H.: Stereo processing by semi-global matching and mutual information. IEEE Transactions on Pattern Analysis and Machine Intelligence, vol. 30 n$^{\circ}$, pp. 328--341. (2008)

27. Remondino, F., El-Hakim, S., Gruen, A., Zhang, L.: Development and performance analysis of image matching for detailed surface reconstruction of heritage objects. IEEE Signal Processing Magazine, vol. 25 n4, pp. 55--65. (2008)

28. Hiep, V.H., Keriven, R., Labatut, P., Pons, J.P.: Towards high-resolution large-scale multiview stereo. In: Proceedings CVPR, Kyoto, Japan (2009)

29. Furukawa, Y. and Ponce, J.: Accurate, dense and robust multiview stereopsis. IEEE Transactions on Pattern Analysis and Machine Intelligence, vol. 32 n8, pp. 1362--1376. (2010)

30. Jachiet, A.L., Labatut, P., Pons, J.P.: Robust piecewise-planar 3D reconstruction and completion from large-scale unstructured point data. In: Proceedings CVPR, San Francisco, USA (2010)

31. Pierrot-Deseilligny, M., De Luca, L., Remondino, F.: Automated Image-Based Procedures for Accurate Artifacts 3D Modeling and Orthoimage. In: XXIIIth International CIPA Symposium (2011)

32. Remondino, F., Lo Buglio, D., Nony, N., De Luca, L.: Detailed primitive-based 3d modeling of architectural elements. In: Proceedings of The XXII Congress of the International Society for Photogrammetry and Remote Sensing. Melbourne, Australia (2012) 